\title{
Atividade ovicida e larvicida do extrato hidroalcoólico de Artemisia annua sobre parasitas gastrintestinais de bovinos
}

\author{
[Ovicidal and larvicidal activity of Artemisia annua hydroalcoholic extract against \\ gastrointestinal parasites in cattle] \\ L.K. Sprenger ${ }^{1}$, A. Buzatti ${ }^{1}$, L.H. Campestrini ${ }^{1}$, F.T. Yamassaki ${ }^{1}$, J.B.B. Maurer ${ }^{1}$, \\ S.F.Z. Baggio ${ }^{1}$, P.M. Magalhães ${ }^{2}$, M.B. Molento ${ }^{1 *}$ \\ ${ }^{1}$ Universidade Federal do Paraná - UFPR - Curitiba, PR \\ ${ }^{2} \mathrm{CPQBA}$ - Universidade Estadual de Campinas - UNICAMP - Paulínia, SP
}

\begin{abstract}
RESUMO
Os parasitas gastrintestinais causam enorme prejuízo econômico na bovinocultura, tanto nacional como mundial, ocasionado principalmente por Bunostumom sp., Cooperia sp. e Trichostrongylus sp. O objetivo deste trabalho foi determinar a eficácia in vitro do extrato hidroalcoólico de Artemisia annua (H.7) frente a esses endoparasitas. $\mathrm{O}$ H.7 foi produzido com sete dias de percolação a $4^{\circ} \mathrm{C}$ e posteriormente liofilizado. Com esse fitoterápico, realizaram-se testes de eclodibilidade de ovos (TEO) e de migração larvar em ágar (TMLA), com seis repetições, com concentrações crescentes $(0,78$ a $50 \mathrm{mg} / \mathrm{mL})$. Para analisar a composição química do fitoterápico, procedeu-se à marcha fitoquímica completa. No TEO, a eficácia variou de $94,08 \pm 2,58 \%$ na maior concentração a $15,67 \pm 0,97 \%$ na menor concentração. Já no TMLA os valores encontrados variaram de $90,05 \pm 0,55 \%$ a $4,12 \pm 0,46 \%$. Nas análises fitoquímicas, foram encontrados diversos compostos com propriedades de combater os nematódeos, tanto direta como indiretamente. Os resultados obtidos nos testes in vitro evidenciam que o extrato produzido possui potencial de combater nematódeos gastrintestinais de bovinos. Novos estudos devem ser realizados buscando maximizar a eficácia do H.7 e de outras extrações obtidas a partir de A. annua, uma vez que foram demonstrados excelentes resultados em ambos os experimentos.
\end{abstract}

Palavras-chave: controle alternativo, fitoterapia, resistência parasitária

\begin{abstract}
Gastrointestinal parasites cause economic losses to the cattle production, in Brazil and worldwide, mainly caused by Bunostumom sp., Cooperia sp. and Trichostrongylus sp. The aim of this study was to determine the in vitro efficacy of hydroalcoholic extract of Artemisia annua (H.7) against these parasites. The $H .7$ was produced after 7 days of storage at $4{ }^{\circ} \mathrm{C}$ and then lyophilized. With this herbal the egg hatch test (EHT) and larval migration inhibition (LMI) were performed, in six replicates with different concentrations $(0.78$ to $50 \mathrm{mg} / \mathrm{mL})$. To analyze the chemistry composition the complete phytochemical screening was done. In EHT efficiency ranged from $94.08 \pm 2.58 \%$ at the highest concentration to $15.67 \pm$ $0.97 \%$ in the lowest concentration. In LMI test the values ranged from $90.05 \pm 0.55 \%$ to $4.12 \pm 0.46 \%$. Phytochemical tests showed many chemical compounds with anthelmintic properties. The results obtained in biochemical tests together with those found in in vitro tests showed that the extract produced has the potential to combat intestinal nematodes of cattle. Further studies should be conducted to maximize the effectiveness of $\mathrm{H} .7$ and other extractions from A. annua, because it demonstrated excellent results in both experiments.
\end{abstract}

Keywords: alternative methods, herbal medicine, parasitic resistance

Recebido em 14 de agosto de 2013

Aceito em 4 de agosto de 2014

*Autor para correspondência (corresponding author)

E-mail: molento@ufpr.br 


\section{INTRODUÇÃO}

Historicamente, o agronegócio tem grande destaque na economia brasileira, contribuindo de forma expressiva para o balanço mercantil do país, sendo a bovinocultura um dos principais geradores de divisas. O país possui o segundo maior rebanho comercial do planeta, com mais de 210 milhões de cabeças. Apesar do enorme potencial da atividade, existem alguns entraves sanitários que diminuem a produtividade, sendo o principal deles as parasitoses gastrintestinais, que geram deficits econômicos significativos (Cezar et al., 2010). Isso decorre devido aos sinais clínicos decorrentes das infecções, entre eles: anorexia, apatia, aumento da conversão alimentar, comprometimento da função reprodutiva, diarreia, diminuição da produção leiteira e perda de peso. Os principais endoparasitas de bovinos são: Bunostumom sp. e Cooperia sp., localizados no intestino delgado; Haemonchus sp. e Trichostrongylus sp., situados no abomaso (Molento, 2014, UFPR).

O controle da enfermidade é fundamental, sendo geralmente realizado de forma intensiva, com o uso indiscriminado de anti-helmínticos comerciais, sem considerar os fatores epidemiológicos envolvidos (Condi et al., 2009). Contudo, a utilização supressiva dos fármacos aliada às falhas de manejo contribui para o estabelecimento de parasitas resistentes a esses produtos. Devido à expressão genética diferenciada, a eficácia de qualquer fármaco antiparasitário pode diminuir, favorecendo a permanência e propagação da população parasitária resistente e a eliminação dos indivíduos susceptíveis (Molento, 2005). Outro problema é a presença de resíduos de antiparasitários no meio ambiente, que, quando usados em demasia, podem gerar sérios distúrbios ecológicos de modo mais rápido (Diao et al., 2007). Além disso, a contaminação dos produtos de origem animal com resíduos farmacológicos e a conscientização da população em relação à importância de alimentos livres desses resíduos são fatores que evidenciam a importância de pesquisas por métodos alternativos de controle parasitário.

Diante desses fatores acima citados, vários estudos estão sendo realizados buscando contornar tal situação. Entre as diversas tecnologias desenvolvidas, o uso de produtos fitoterápicos é que se encontra em fase mais avançada de pesquisa e demonstrando resultados promissores.

Entre as diversas plantas pesquisadas na atualidade, Artemisia annua se destaca como uma das potenciais soluções para auxiliar no controle parasitário dos animais de produção (Hasheminia et al., 2011). Popularmente conhecida no Brasil como Artemísia ou Erva-deSão-João, é uma planta de origem chinesa, cultivada por determinados centros de pesquisa nacionais. Em alguns países, é utilizada no tratamento, em humanos, de enfermidades como malária, hepatite, hipertensão, icterícia, inflamações e infecções fúngicas, bacterianas e virais (Rustaiyan e Masoudi, 2011).

Na medicina veterinária, há inúmeros relatos de sucesso na utilização de fitoterápicos produzidos a partir dessa planta frente a diversos parasitas (Brisibe et al., 2008; Tariq et al., 2009), contudo não existem trabalhos realizados testando sua eficácia in vitro frente aos parasitas gastrintestinais de bovinos. Devido à falta de dados científicos, o presente estudo foi desenvolvido com o objetivo de avaliar a eficácia de extratos produzidos a partir de Artemisia annua no controle de nematódeos gastrintestinais de bovinos, utilizando testes in vitro.

\section{MATERIAL E MÉTODOS}

A Artemisia annua utilizada neste experimento foi plantada e colhida no Centro Pluridisciplinar de Pesquisas Químicas, Biológicas e Agrícolas (CPQBA) da Universidade de Campinas (UNICAMP). A espécie está depositada no herbário do CPQBA sob o número 979.

Após a colheita das folhas, estas foram secadas à sombra e trituradas em moinho, em seguida o material foi inspecionado para retirada de partículas estranhas e posteriormente armazenado ao abrigo de luz e umidade.

Para extração hidroalcoólica, utilizou-se um frasco de cor âmbar, vedado com papel alumínio, no qual foram colocados $64 \mathrm{~g}$ das folhas junto com 640mL de álcool 80\% (v/v). Nessa extração, produziu-se o extrato hidroalcoólico de sete dias (H.7), o qual ficou armazenado a $4^{\circ} \mathrm{C}$ por uma semana. Durante o período, houve agitação periódica do conteúdo. Após essa etapa, realizou- 
se a filtração. $O$ extrato foi concentrado em evaporador rotatório, sob pressão reduzida e à temperatura inferior a $30^{\circ} \mathrm{C}$, para posteriormente ser liofilizado. $\mathrm{O}$ rendimento obtido em relação às folhas foi de $5,89 \%$.

$\mathrm{w}$

Posteriormente se realizou a marcha fitoquímica qualitativa adaptada de Matos (1998), cuja modificação foi realizar apenas a avaliação da presença dos seguintes metabólitos secundários: alcaloides, antocianinas, antocianidinas, esteroides, fenois, flavonoides, leucoantocianidinas, resinas, saponinas, taninos, e triterpenos.

A dosagem de compostos fenólicos totais foi realizada pelo teste de Folin-Ciocalteu, seguindo a metodologia adaptada por McDonald et al. (2001), em que o teor de fenóis totais (FT) é determinado pela interpolação da absorbância das amostras contra a curva de calibração construída somente com padrões de ácido gálico. Os resultados, determinados a partir da equação de regressão da curva de calibração $(y=0,02 x$ 0,$0064 ; R^{2}=0,9911$ ), foram expressos em $\mathrm{mg}$ de ácido gálico equivalentes por grama da amostra.

A dosagem e quantificação de artemisinina foram realizadas nos laboratórios de fitoquímica do CPQBA-UNICAMP, pelo método de cromatografia líquida de alta eficiência (CLAE), seguindo o protocolo utilizado por Celeghini et al. (2009).

Para a recuperação dos ovos, coletaram-se fezes diretamente da ampola retal de bovinos, previamente selecionados, com OPG superior a 1.000. Um pool de 30 gramas de fezes foi processado seguindo o protocolo de Coles et al. (1992), adaptado por Bizimenyera et al. (2006). Seguindo as modificações do protocolo, as fezes foram maceradas e homogeneizadas em água aquecida a $40^{\circ} \mathrm{C}$ e filtradas em uma sequência de peneiras com malhas contendo aberturas de $400 \mu \mathrm{m}, 250 \mu \mathrm{m}, 150 \mu \mathrm{m}, 75 \mu \mathrm{m}$ e $25 \mu \mathrm{m}$. Após essa lavagem com água destilada, os ovos foram coletados da última peneira e distribuídos em tubos tipo Falcon de $50 \mathrm{~mL}$ e centrifugados em $3.000 \mathrm{rpm}$, por 3 minutos, para em seguida ser descartado o sobrenadante e completar-se com solução salina saturada para a ressuspensão do sedimento. Novamente o material foi centrifugado nas mesmas condições que anteriormente e o sobrenadante foi lavado na peneira de $25 \mu \mathrm{m}$ com água destilada, até a retirada total da solução salina. $O$ conteúdo foi transferido para um Becker e quantificado em alíquotas de $55 \mu \mathrm{L}$ com aproximadamente 200 ovos.

O protocolo utilizado para o Teste de Eclodibilidade de Ovos (TEO) foi descrito por Coles et al. (1992), modificado por Bizimenyera et al. (2006). Para seguir a adaptação, aproximadamente $55 \mu \mathrm{L}$ da suspensão contendo 200 ovos foram acondicionados em cada poço de placas de 24 poços. Calculado o volume final de $1 \mathrm{~mL}$ para cada poço, os tratamentos fitoterápicos foram preparados nas concentrações: $50 ; 25$; $12.5 ; \quad 6.25 ; \quad 3.125 ; 1.562$ e $0.781 \mathrm{mg} / \mathrm{mL}$. Objetivando a melhor diluição do extrato, foi adicionado DMSO a $3 \%$. O controle negativo foi feito com água destilada; já os controles positivos foram realizados com o emulsificante DMSO aquoso a $3 \%(\mathrm{v} / \mathrm{v})$ e o outro com albendazol $0,63 \mathrm{mg} / \mathrm{mL}$. A contagem dos ovos e das larvas foi realizada em microscópio invertido. Seis replicatas foram realizadas para cada tratamento e também para os controles. No cálculo da porcentagem de eficácia, utilizou-se a seguinte fórmula:

Eclodibilidade $(\%)=L 1 /($ ovos + L1 $) \times 100$

Para a realização do Teste de Migração de Larvas em Ágar (TMLA), foi utilizada a metodologia desenvolvida por D’Assonville et al. (1996) e modificada por Molento e Prichard (2001). Previamente, foi realizada uma coprocultura de um pool de fezes de bovinos. Após 7 dias, as larvas foram coletadas e identificadas: $41 \%$ Trichostrongylus sp., $37 \%$ Cooperia sp., 22\% Bunostumom sp. Foram adicionados $0,5 \mathrm{~mL}$ de solução contendo 200 larvas e $0,5 \mathrm{~mL}$ dos tratamentos em diferentes concentrações diluídos em DMSO 3\% (50; 25; $12.5 ; \quad 6.25 ; \quad 3.125 ; \quad 1.562$ e $0.781 \mathrm{mg} / \mathrm{mL})$, adicionados de água destilada para completar o volume. $\mathrm{O}$ controle negativo foi feito com água destilada; já o controle positivo foi realizado com o emulsificante DMSO a $3 \%$ e o outro com moxidectina $0,63 \mathrm{mg} / \mathrm{mL}$. Após homogeneização, essa solução foi mantida nas mesmas condições por mais $6 \mathrm{~h}$. Transcorrido esse período, colocouse $1 \mathrm{~mL}$ de solução de ágar, $1,4 \%(\mathrm{~m} / \mathrm{v})$ a $45^{\circ} \mathrm{C}$ e transferiu-se tudo para uma placa de Petri. Essa placa foi mantida em estufa B.O.D a $27^{\circ} \mathrm{C}$ por 18h. Transcorrido esse tempo, a porção líquida foi transferida para um tubo plástico de $50 \mathrm{~mL}$, 
centrifugada a 2.000 rpm por $3 \mathrm{~min}$, para então serem transferidas placas de 24 poços. Por fim, fez-se a contagem das larvas migrantes em microscópio invertido. Seis replicatas foram realizadas para cada tratamento e também para os controles.

$\mathrm{Na}$ realização da análise estatística, os dados foram avaliados por análise de variância (ANOVA), seguida do teste Tukey, em que foram considerados estatisticamente diferentes os resultados que apresentaram probabilidade de ocorrência da hipótese de nulidade menor que $5 \%(P<0,05)$. Todas as análises foram realizadas usando-se o programa GraphPad Prism® 5.

\section{RESULTADOS}

Após a realização da marcha fitoquímica, foram detectadas as presenças dos seguintes metabólitos: alcaloides, catequinas, esteroides, fenóis, resinas, taninos e triterpenos; ao passo que antocianinas, antocianidinas e leucoantocianidinas não foram encontradas pelos testes utilizados. O teor de fenóis totais, em equivalentes de ácido gálico, foi $203,0 \pm 0,569 \mu \mathrm{g} / \mathrm{L}$. A dosagem de artemisinina em CLAE indicou a concentração de $59,409 \pm 1,472 \mu \mathrm{g} / \mathrm{dL}$ no produto.

Os resultados do teste de inibição da eclodibilidade dos ovos e teste de migração de larvas em ágar estão ilustrados na Tabela 1. O melhor valor de eficácia para o TEO foi encontrado na concentração de $50 \mathrm{mg} / \mathrm{mL}$ $(94,08 \pm 2,58 \%)$, sendo esse valor semelhante ao controle positivo $(98,42 \pm 1,34 \%)(\mathrm{P}<0,05)$. Já no TMLA, o melhor resultado também ocorreu na concentração de $50 \mathrm{mg} / \mathrm{mL} \quad(90,05 \pm 0,55 \%)$, o qual foi semelhante ao controle positivo desse teste $(96,04 \pm 0,79 \%)(\mathrm{P}<0,05)$. Os resultados, em ambos os testes, demonstraram um efeito dosedependente, em que, quanto maior a concentração dos extratos, maior o efeito sobre os ovos e larvas.

Tabela 1. Percentual médio ( \pm desvio padrão) de inibição da eclosão de ovos de nematódeos gastrintestinais no teste TEO e inibição da migração larvar TMLA do extrato hidroalcoólico de sete dias obtido de Artemisia annua

\begin{tabular}{|c|c|c|}
\hline Concentração $(\mathrm{mg} / \mathrm{mL})$ & TEO & TMLA \\
\hline 50,0 & $94,08 \pm 2,58 \% \mathrm{~A}$ & $90,05 \pm 0,55 \% \mathrm{~A}$ \\
\hline 25,0 & $88,43 \pm 0,76 \% \mathrm{~A}$ & $80,47 \pm 0,82 \% \mathrm{~A}$ \\
\hline 12,5 & $83,03 \pm 1,23 \% \mathrm{~A}$ & $59,03 \pm 1,22 \% \mathrm{~B}$ \\
\hline 6,25 & $67,03 \pm 0,26 \% \mathrm{~B}$ & $40,33 \pm 0,97 \% \mathrm{C}$ \\
\hline 3,12 & $46,99 \pm 0,29 \% \mathrm{C}$ & $23,52 \pm 1,79 \% \mathrm{D}$ \\
\hline 1,56 & $28,37 \pm 1,17 \% \mathrm{D}$ & $10,24 \pm 1,73 \% \mathrm{E}$ \\
\hline 0,78 & $15,67 \pm 1,34 \% \mathrm{E}$ & $4,12 \pm 0,46 \% \mathrm{~F}$ \\
\hline $\mathrm{C}-\mathrm{DMSO}(3 \%)$ & $1,32 \pm 0,39 \% \mathrm{G}$ & \\
\hline $\mathrm{C}+{ }^{\mathrm{TEO}}$ & & - \\
\hline $\mathrm{C}+{ }^{\mathrm{TMLA}}$ & $98,42 \pm 1,34 \% \mathrm{~A}$ & $96,28 \% \mathrm{G}$ \\
\hline $\mathrm{CL}_{50}$ & - & $9,24 \mathrm{mg} / \mathrm{mL}$ \\
\hline
\end{tabular}

$\mathrm{C}$ : Água destilada; $\mathrm{C}+{ }^{\mathrm{TEO}}$ : albendazol $0,63 \mathrm{mg} / \mathrm{mL} ; \mathrm{C}+{ }^{\mathrm{TMLA}}$ : moxidectina $0,63 \mathrm{mg} / \mathrm{mL} ; \mathrm{CL}_{50}$ : concentração letal para $50 \%$ dos ovos. Letras maiúsculas comparam médias nas colunas; letras dessemelhantes indicam diferença significativa $(\mathrm{P}<0,05)$.

\section{DISCUSSÃO}

A realização da análise química dos fitoterápicos candidatos a antiparasitários é de suma importância, pois assim pode-se aprofundar na origem da atividade terapêutica e na qualidade dos produtos. Os resultados encontrados na marcha fitoquímica realizada neste trabalho corroboram a literatura científica (Brisibe et al.,
2009). Entre os principais responsáveis pela atividade anti-helmíntica da $A$. annua, destacamse os flavonoides, taninos e artemisinina (O’Neill et al., 2010).

Os flavonoides, há anos, vêm sendo relacionados com efeitos positivos na saúde dos animais, devido principalmente à sua atividade antioxidante, que possui efeito direto sobre a 
redução do envelhecimento celular e melhora da imunidade (Ferreira et al., 2010). O mecanismo de ação dos taninos ocorre pela redução da excreção dos ovos dos nematódeos e diminuição da fertilidade das fêmeas adultas. Outro importante fator é a redução da motilidade das larvas, o que diminui a taxa de contaminação da pastagem (Molan et al., 2003). Comprovou-se que animais parasitados, quando expostos a pastos com diferentes tipos de forrageiras, tendem a consumir plantas com grande teor de tanino (Lisonbee et al., 2009). Essa ingestão ocorre pela associação estabelecida pelos animais de que o consumo de plantas com elevado teor desse composto reduz a carga parasitária. A artemisinina é apontada como o principal responsável pela ação anti-helmíntica dos extratos produzidos com A. аппиа. Esse metabólito interfere nas proteínas mitocondriais de transporte do parasita e modula beneficamente o sistema imune do hospedeiro (Hoste et al., 2010).

Os flavonoides, taninos e artemisinina são os principais responsáveis pela atividade antihelmíntica, todavia as cumarinas, compostos esteroides, fenóis, purinas e triterpenoides são imunomoduladores, mecanismo vital para animais parasitados potencializam o efeito (Brisibe et al., 2009). Essas moléculas também melhoram a absorção do medicamento, potencializando a atividade farmacológica e prolongando a permanência no organismo (Blanke et al., 2008). Além disso, a planta possui metabólitos capazes de produzir respostas próinflamatórias, as quais são importantes para os desafios parasitários enfrentados pelos animais (Tariq et al., 2009).

Até o presente momento, em parasitologia, os fitoterápicos produzidos a partir de A. апnиa tiveram sua eficácia comprovada frente a diversos parasitas, como: Babesia equi, Clonorchis sinensis, Cryptosporidium sp., Eimeria sp., Entemoeba histolytica, Giardia intestinalis, Leishmania sp., Opisthorchis viverrini, Plasmidium falciparum, Schistosoma japonicum, S. haemotobium, S. mansoni, Trypanosoma sp. (Brisibe et al., 2008). Especificamente em bovinos, foi provado o efeito para Eimeria sp., Fasciola hepatica, Neospora caninum, Toxoplasma gondii.
A pecuária, assim como qualquer outra atividade econômica, necessita sempre minimizar as perdas produtivas, visando à maximização dos lucros. O prejuízo causado por parasitas gastrintestinais em bovinos, principalmente Bunostumom sp., Cooperia sp. e Trichostrongylus sp., é estimado em 1,7 bilhões de reais, devido ao significativo decréscimo nos índices zootécnicos. No mundo, a prevalência desses endoparasitas pode variar de acordo com o clima, localização geográfica e período do ano estudado (Cezar et al., 2010). Todavia, no Brasil, os três helmintos encontram-se difundidos por todo o território nacional (Santos et al., 2010). Logo, é primordial o controle das infecções ocasionadas por esses nematódeos para melhorar a produtividade na bovinocultura.

Mesmo existindo diversos estudos evidenciando o efeito antiparasitário dos extratos produzidos a partir de $A$. апnиa, nunca houve pesquisas visando elucidar a ação frente a esses importantes endoparasitas de bovinos. Essa planta possui várias propriedades farmacológicas descobertas, contudo muitas ainda podem ser descobertas devido à diversidade de compostos existentes em sua estrutura (Brisibe et al., 2008). Os extratos demonstraram desempenho promissor, mesmo quando comparados com os controles positivos, o que evidencia a potente atividade antiparasitária da planta.

O $\quad$ H.7 demonstrou atividade de inibição da eclodibilidade de ovos dose-dependentes e atingiu eficácia superior a $90 \%$ somente na concentração de $50 \mathrm{mg} / \mathrm{mL}$. Diversos compostos fitoterápicos, produzidos a partir de diferentes plantas, já foram testados no TEO com ovos de nematódeos gastrintestinais de bovinos (AlonsoDíaz et al., 2011). Extrato aquoso de Caryocar brasiliense demonstrou inibição da eclosão dos ovos maior que $90 \%$ em dosagem superior a $7,35 \mathrm{mg} / \mathrm{mL}$ (Nogueira et al., 2012). Extratos aquosos produzidos com as folhas, cascas e raízes de Peltophorum africanum inibiram $100 \%$ a eclodibilidade dos ovos de parasitas gastrintestinais de bovinos ao serem utilizados na concentração de $5 \mathrm{mg} / \mathrm{mL}$ (Bizimenyera et al., 2006). Extrato hidroalcoólico de Origanum vulgare na concentração de $40 \mathrm{mg} / \mathrm{mL}$ inibiu $100 \%$ a eclosão de ovos de nematódeos gastrintestinais de bovinos (Castro et al., 2013). 
No TMLA foi evidenciada uma atividade em outros fitoterápicos testados em parasitas gastrintestinais de bovinos descritos na literatura. Em trabalho realizado utilizando-se extrato de acetona com folhas de Pistacia lentiscus, Quercus coccifera, Ceratonia siliqua, Castanea sativa, Pyrus spinosa e Onobrychis viciifolia foi demonstrado que $1,2 \mathrm{mg} / \mathrm{mL}$ desses extratos inibiram em 79,$1 ; 63,8 ; 61,5 ; 54,6 ; 47,4$ e $38,9 \%$ a migração larval, respectivamente (Manolaraki et al., 2010). Utilizando-se a concentração de $1.200 \mathrm{mg} / \mathrm{mL}$ de extratos de acetona produzidos com folhas de Acacia gaumeri, Brosimum alicastrum, Havardia albicans e Leucaena leucocephala obtiveram-se resultados inferiores a 50\% de eficácia (Alonso-Díaz et al., 2011). É importante enfatizar que os resultados encontrados no TEO são inferiores ao TMLA, em todas as concentrações testadas, o que também foi observado na literatura científica consultada.

\section{CONCLUSÕES}

Com base nos resultados obtidos, concluiu-se que o extrato obtido pela metodologia descrita no presente experimento demonstrou ser candidato a fitoterápico antiparasitário para nematódeos de bovinos. Os exames bioquímicos apontaram a presença de diversos compostos químicos que possuem a capacidade de combater parasitas, tanto direto como indiretamente, apontando um possível sucesso no controle anti-helmíntico na bovinocultura. Novos estudos devem ser realizados buscando maximizar a eficácia do produto e posteriormente aplicá-lo em testes in vivo.

\section{AGRADECIMENTOS}

Os autores agradecem à farmacêutica Iara Bolson Beleze (CPQBA-Unicamp) pelo auxílio das análises de dosagem de artemisinina por CLAE. Os autores também agradecem pelo auxílio financeiro do PRONEX-Carboidratos (CNPq/Fundação Araucária) e da UGF/SETI-Pr (convênio 43/08).

\section{REFERÊNCIAS}

ALONSO-DÍAZ, M.A.; TORRES-ACOSTA, J.F.J.; SANDOVAL-CASTRO, C.A. et al. Comparing the sensitivity of two in vitro assays to evaluate the anthelmintic activity of tropical tannin rich plant extracts against Haemonchus contortus. Vet. Parasitol., v.181, p.360-364, 2011.

BIZIMENYERA, E.S.; GITHIORI, J.B.; ELOFF, J.N. et al. In vitro activity of Peltophorum africanum Sond. (Fabacea) extracts on the egg hatching and larval development of the parasitic nematode Trichostrongylus colubriformis. Vet. Parasitol., v.142, p.336-343, 2006.

BLANKE, C.H.; NAISABHA, G.B.; BALEMA, M.B. et al. Herba Artemisiae annuae tea preparation compared to sulfadoxinepyrimethamine in the treatment of uncomplicated falciparum malaria in adults: a randomized double-blind clinical trial. Trop. Doc., v.38, p.113-116, 2008.

BRISIBE, E.A.; UMOREN, U.E.; BRISIBE, F. et al. Nutritional characterisation and antioxidant capacity of different tissues of Artemisia annua L. Food Chem., v.115, p.1240-1246, 2009.

BRISIBE, E.A.; UMOREN, U.E.; OWAI, P.U. et al. Dietary inclusion of dried Artemisia annua leaves for management of coccidiosis and growth enhancement in chickens. Afr. J. Biotechnol., v.7, p.4083-4092, 2008.

CASTRO, L.L.D.D.; MADRID, I.M.; AGUIAR, C.L.G. et al. Origanum vulgare (Lamiaceae) ovicidal potential on castrointestinal nematodes of cattle. Cien. Anim. Bras., v.14, p.508-513, 2013.

CELEGHINI, R.M.D.S.; SOUSA, I.M.D.O.; SILVA, A.P.D. et al. Development and validation of analytical methodology by HPLCIR for evaluation of artemisinin on Artemisa annua L. Quim. Nova, v.32, p.875-878, 2009.

CEZAR, A.S.; VOGEL, F.S.; SANGIONI, L.A. et al. Ação anti-helmíntica de diferentes formulações de lactonas macrocíclicas em cepas resistentes de nematódeos de bovinos. Pesq. Vet. Bras, v.30, p.523-528, 2010. 
COLES, G.C.; BAUER, C.; BORGSTEEDE, F.H.M. et al. World Association for the Advancement of Veterinary Parasitology (WAAVP) - methods for detection of anthelmintic resistance in nematodes of veterinary importance. Vet. Parasitol., v.44, p.35-44, 1992.

CONDI, G.K.; SOUTELLO, R.G.V.; AMARANTE, A.F.T. Moxidectin-resistant nematodes in cattle in Brazil. Vet. Parasitol., v.161, p.213-217, 2009.

D'ASSONVILLE, J.A.; JANOVSKY, E.; VERSTER, A. In vitro screening of Haemonchus contortus third stage larvae for ivermectin resistance. Vet. Parasitol., v.61, p.73-80, 1996.

DIAO, X.; JENSEN, J.; HANSEN, A.D. Toxicity of the anthelmintic abamectin to four species of soil invertebrates. Environ.Pollut., v.148, p.514-519, 2007.

FERREIRA, J.F.; LUTHRIA, D.L.; SASAKI, T. et al. Flavonoids from Artemisia anпиa L. as antioxidants and their potential synergism with artemisinin against malaria and cancer. Molecules, v.15, p.3135-3170, 2010.

HASHEMINIA, S.M.; SENDI, J.J.; JAHROMI, K.T. et al. The effects of Artemisia annua L. and Achillea millefolium L. crude leaf extracts on the toxicity, development, feeding efficiency and chemical activities of small cabbage Pieris rapae L. (Lepidoptera: Pieridae). Pestic. Biochem. Phys., v.99, p.244-249, 2011.

HOSTE, H.; SOTIRAKI, S.; LANDAU, S.Y. et al. Goat- nematode interactions: think differently. Trends Parasitol., v.26, p.376-381, 2010 .

LISONBEE, L.D.; VILLALBA, J.J.; PROVENZA, F.D. et al. Tannins and self-medication: Implications for sustainable parasite control in herbivores. Behav. Process., v.82, p.184-189, 2009.

MANOLARAKI, F.; SOTIRAKI, S.; STEFANAKIS, A. et al. Anthelmintic activity of some Mediterranean browse plants against parasitic nematodes. Parasitology, v.137, p.685-696, 2010 .
MATOS, F.J.A. Farmácias vivas. 3 ed. Fortaleza: Edições UFC, 1998. 220p.

MCDONALD, S.; PRENZLER, P.D.; ANTOLOVICH, M. et al. Phenolic content and antioxidant activity of olive extracts. Food Chem., v.73, p.73-84, 2001.

MOLAN, A.; DUNCAN, A.; BARRY, T. et al. Effects of condensed tannins and crude sesquiterpene lactones extracted from chicory on the motility of larvae of deer lungworm and gastrointestinal nematodes. Parasitology, v.52, p.209-218, 2003.

MOLENTO, M.B. Resistência parasitaria em helmintos de equídeos e propostas de manejo. Cienc. Rural, v.35, p.1469-1477, 2005.

MOLENTO, M.B.; PRICHARD, R.K. Efeito de drogas moduladoras da resistência múltipla na atividade da ivermectina e moxidectina contra larvas infectantes selecionadas de Haemonchus contortus. Pesq. Vet. Bras., v.21, p.117-121, 2001.

NOGUEIRA, F.A.; FONSECA, L.D.; DA SILVA, R.B. et al. In vitro and in vivo efficacy of aqueous extract of Caryocar brasiliense Camb. to control gastrointestinal nematodes in sheep. Parasitol. Res., v.111, p.325-330, 2012.

O’NEILL, P.M.; BARTON, V.E.; WARD, S.A. The molecular mechanism of action of artemisinin-The debate continues. Molecules, v.15, p.1705-1721, 2010.

RUSTAIYAN, A.; MASOUD, S. Chemical constituents and biological activities of Iranian Artemisia species. Phytochem. Lett., v.247, p.440-447, 2011.

SANTOS, F.C.C.; MONTEIRO, S.G.; ROLL, V.F. Efeito in vitro da associação de citronela, erva de santa maria e quássia sobre o carrapato bovino Rhipicephalus (Boophilus) microplus. Cienc. Anim. Bras., v.14, p.13-119, 2013.

TARIQ, K.A.; Chishti, M.Z.; Ahmad, F. et al. Anthelmintic activity of extracts of Artemisia absinthium against ovine nematodes. Vet. Parasitol., v.160, p.83-88, 2009. 